\title{
FIGO Stage II Ovarian Cancer
}

National Cancer Institute

\section{Source}

National Cancer Institute. FlGO Stage II Ovarian Cancer. NCI Thesaurus. Code C128085.

Ovarian cancer involving one or both ovaries with pelvic extension (below the pelvic brim) or primary peritoneal cancer. (FIGO, 2014) 